\title{
DA ARTICULAÇÃO DO TRABALHO COLETIVO AO CONTROLE DO TRABALHO DOCENTE: OS (DES)CAMINHOS LEGAIS DA COORDENAÇÃO PEDAGÓGICA NO ESTADO DE SÃO PAULO*
}

\author{
FROM THE ARTICULATION OF COLLECTIVE WORK \\ TO THE CONTROL OF TEACHING WORK: THE LEGAL \\ (NON-) PATHWAYS OF PEDAGOGICAL COORDINATION \\ IN THE STATE OF SÃO PAULO
}

\section{DE LA ARTICULACIÓN DEL TRABAJO COLECTIVO AL CONTROL DEL TRABAJO DOCENTE: (DES)CAMINOS LEGALES DE LA COORDINACIÓN PEDAGÓGICA EN EL ESTADO DE SÃO PAULO}

Maria José da Silva Fernandes Universidade Estadual Paulista - UNESP

Resumo Neste artigo são apresentados os resultados de uma pesquisa documental centrada na análise das resoluções publicadas no período de 1996 a 2017 sobre a função de Professor Coordenador (PC) no Estado de São Paulo. Foram analisadas 11 resoluções específicas, destacando-se os elementos centrais que alteraram a natureza do trabalho da função, como as justificativas, formas de seleção, denominação e, principalmente, as atribuições a serem realizadas nas escolas. O período analisado corresponde justamente ao fortalecimento das reformas educacionais de natureza neoliberal que ocorreram na rede paulista, na qual medidas gerencialistas e performáticas determinadas no âmbito de programas e projetos alteraram a organização do trabalho pedagógico. Nesse sentido, a legislação foi um importante instrumento normativo que levou a coordenação pedagógica a adquirir novos sentidos na prática escolar. A função eminentemente articuladora e voltada para o exercício de atividades pedagógicas relacionadas às necessidades específicas das escolas por meio da elaboração e desen-

* Artigo apresentado com alterações no XXVIII Simpósio Brasileiro de Política e Administração da Educação, realizado na Universidade Federal da Paraíba no ano de 2017. 
volvimento do Projeto Político Pedagógico foi apropriada com outros objetivos e intenções ao longo de mais de 20 anos de implantação das políticas educacionais no Estado, tornando-se mais controladora e voltada ao monitoramento das ações determinadas externamente.

Palavras-chave: Coordenação Pedagógica; Professor Coordenador; Reformas Educacionais; Rede Pública Estadual Paulista.

Abstract This paper presents the results of a documentary research focused on the analysis of the published resolutions from 1996 to 2017 on the role of the Coordinating Teacher (CT) in the State of São Paulo. Eleven specific resolutions were analyzed and the main elements that changed the nature of the function were highlighted, as justification, selection, denomination and, especially, the assignments to be carried out in schools. The analyzed period corresponds precisely to the strengthening of neoliberal educational reforms that took place in the São Paulo network, in which managerial and performance measures determined in the scope of programs and projects changed the organization of pedagogical work. In this sense, legislation was an important normative instrument that allowed pedagogical coordination to acquire new meanings in school practice. The eminently articulating and oriented function for the exercise of pedagogical activities related to the specific needs of schools through the elaboration and development of the Pedagogical Political Project appropriated other objectives and intentions throughout more than 20 years of educational policies implementation in the State, becoming more controlling and focused on the monitoring of externally determined actions.

Key-words: Pedagogical Coordination; Coordinating Teacher; Educational Reforms; São Paulo Public Network.

RESUMEN En este articulo son presentados los resultados de una pesquisa documental centrada en el analisis de las resoluciones publicadas en el periodo del 1996 a 2017 sobre la funciõn del profesor coordenador (PC) en el estado de São Paulo. Fueron analisadas 11 resoluciones específicas, destacandose los elementos cetrales que alteraron la naturaleza del trabajo de la funciõn, como las justificativas, formas de selección, denominación y principalmente las atribuciones a ser realizadas en las escuelas. El periodo analizado corresponde justamente al fortalecimiento de las reformas educacionales de naturaleza neoliberal que ocurrieron en la red paulista, en la cual medidas gerencialistas y performaticas determinadas en el ambito de programas y proyectos alteraron la organización del trabajo pedagógico. En este sentido, la legislación fue un importante instrumento normativo que llevo a la coordinación pedagógica a adquirir nuevos sentidos en la práctica escolar. La función, eminentemente articuladora es dirigida para el ejercicio de actividades pedagógicas relacionadas a las necesidades específicas de las escuelas por medio de la elaboración y desarrollo del Proyecto Politico Pedagógico, fue apropiada con otros objetivos e intenciones a lo largo de 20 años de implantación de las políticas educacionales en el estado, volviendose mas controladora y dirigida al monitoramiento de las acciones determinadas externamente. Palabras claves: Coordinación Pedagógica; Profesor Coordinador; Reformas Educacionales; Red Pública Estadual Paulista. 


\section{INTRODUÇÃo}

A rede pública de ensino estadual paulista vivenciou desde a segunda metade da década de 1990 a ocorrência de amplas reformas educacionais que impactaram o trabalho docente. Desde as primeiras e marcantes medidas reformistas advindas do projeto "Escola de Cara Nova", em 1996, até o vigente programa "São Paulo faz Escola", iniciado em 2007, ocorreram alterações consideráveis na organização e gestão pedagógica das escolas e das salas de aula, na organização curricular e na composição da carreira e salários docentes. E, embora as reformas do período tenham sido anunciadas em nome de uma suposta "qualidade" da educação, expressas em preocupações oficiais com os resultados quantitativos expressos no desempenho das escolas nas avaliações externas, persistiram e se acumularam os problemas estruturais da educação pública voltada à ampla maioria da população.

Ao longo desse período de mais de vinte anos, sucessivas medidas oficiais foram tomadas, ajustando-se a legislação a um contexto marcado pelo gerencialismo e pela performatividade que, de acordo com Ball (2005, p. 544), funcionaram como mecanismos de reengenharia, de "reforma" e de reconstrução do setor público que passou a conhecer novas orientações, novas relações de poder e novas opções de direcionamento das políticas sociais. Entre as medidas reformistas vinculadas oficialmente ao discurso da "qualidade" que foi levado a cabo pela Secretaria Estadual de Educação (SEE-SP), interessa neste artigo a expansão e consolidação da função de Professor Coordenador (PC). A referida função, presente na maioria das escolas paulistas, é desempenhada por um professor temporariamente designado pelo diretor escolar para realizar as atribuições de coordenação pedagógica. Inicialmente a função se voltava, primordialmente, à organização pedagógica das escolas, à articulação do trabalho coletivo e à formação continuada de professores, atribuições que faziam parte do ideário progressista que defendia a gestão escolar democrática (FERNANDES, 2012). Russo (2011) considerou a coordenação pedagógica como uma prática específica no âmbito da gestão que se contrapunha ao modelo burocrático e autoritário de administração. Dessa forma, a coordenação pedagógica, em seu princípio, constituía-se numa rica possibilidade de atuação docente na mediação dos processos formativos, realizando um trabalho "com" e "para" o coletivo. Entretanto, no âmbito das reformas educacionais com seus novos projetos e programas, mudanças significativas ocorreram na função.

Entre o ano de 1996, quando a coordenação pedagógica foi expandida para a quase totalidade das escolas estaduais, ${ }^{1}$ ao ano de 2017, quando a função completou mais de vinte anos, diferentes resoluções foram publicadas pela Secretaria de Estado da Educação (SEE/ SP) acerca da função, explicitando um maior controle acerca das atividades pedagógicas realizadas pelas escolas e, portanto, sobre a atuação do Professor Coordenador. Nesse período, foram publicadas 11 resoluções - 28/1996, 76/1997, 35/2000, 66/2006, 88/2007, 90/2007, 53/2010, 75/2014, 03/2015 12/2016 e 65/2016 - relacionadas diretamente à função que, em menor ou maior grau, alteraram as atribuições do PC e reduziram as margens

Poderiam ter a função de coordenação pedagógica todas as escolas com mais de dez salas de aula em funcionamento. 
de autonomia das escolas, favorecendo a implantação de uma cultura competitiva marcada por frágil articulação das ações pedagógicas.

Nesse sentido, a coordenação pedagógica, símbolo da democratização das relações pedagógicas nas escolas paulistas, transformou-se, do ponto de vista legal, em mecanismo voltado para a implementação e acompanhamento das ações reformistas. Tendo em vista tal contexto, apresentaremos neste artigo alguns dados decorrentes de análise documental que tomou como corpus as resoluções publicadas acerca da função, problematizando-os frente às reformas educacionais ocorridas no Estado de São Paulo.

\section{Do LABIRINTO DAS RESOLUÇÕES ÀS PRÁTICAS DE CONTROLE NAS ESCOLAS: APON- tamentos sobre a legislação relacionada À CoordenaÇão Pedagógica no Estado de São Paulo}

Ao longo das últimas duas décadas, apenas um único partido político esteve à frente do governo paulista. Nesse longo período, poucos governadores (três nomes principais se revezaram no poder) estiveram à frente do poder executivo, mas, por sua vez, diversos secretários (sete) passaram pela pasta da Educação, impondo diferentes programas e projetos com os quais imprimiram marcas no âmbito da ampla reforma do Estado que teve início em 1996 (PEREIRA, 2007). Foram várias as mudanças no sentido de "dar uma Cara Nova" à educação e de mostrar que "São Paulo faz escola", mas, essencialmente, o que se viu ao longo do referido período foi o aprofundamento das medidas reformistas de natureza performática e gerencialista que adentraram as escolas e alteraram, por meio da legislação, a organização pedagógica e o trabalho docente (FERNANDES, 2012).

As mudanças legais foram muitas e, considerando apenas o caso da função de Professor Coordenador, se publicaram onze diferentes resoluções que alteraram significativamente as atribuições e a natureza da função. As alterações expressaram, por um lado, o estreitamento de uma política de controle que se afirmou em nome de uma suposta qualidade da educação e, por outro, a fragilidade e instabilidade no campo de atuação da coordenação pedagógica assumida na rede estadual como função - portanto, sempre temporária e independente de concurso público. O labirinto legal se caracterizou por novas medidas que alteraram velhas resoluções antes mesmo destas serem amplamente conhecidas e incorporadas ao cotidiano escolar.

Nesse sentido, as mudanças decididas verticalmente pela SEE/SP em relação ao trabalho do Professor Coordenador, considerado oficialmente um dos pilares das reformas educacionais e responsáveis pela melhoria da qualidade da educação (SÃO PAULO, 2007), podem não ter surtido o efeito desejado. A "qualidade", expressa na perspectiva da SEE/SP pelos indicadores de desempenho nas avaliações externas, não apresentou avanços consideráveis, uma vez que o sistema de avaliação paulista - SARESP - continuou com elevado número de alunos abaixo do desempenho considerado satisfatório em todas as etapas de escolaridade nas escolas da rede. Sob outro aspecto, porém, as alterações legais reduzi- 
ram as possibilidades de autonomia dos professores que, controlados, cederam em parte às pressões por desempenho e vivenciaram cotidianamente o esgarçamento do trabalho articulador realizado pela coordenação pedagógica que se voltava às demandas escolares (CUNHA, BARBOSA e FERNANDES, 2015).

Ao considerar o conjunto das resoluções publicadas, um primeiro aspecto se destaca: a própria existência e denominação da função de Professor Coordenador. Desde 1985, há no Artigo 21 do Estatuto do Magistério Paulista a previsão de designação de um professor para desempenhar nas escolas a função de coordenação pedagógica, os denominados "Professores Coordenadores Pedagógicos" - PCP - (SÃO PAULO, 1985). Fruto de um intenso envolvimento da categoria docente, o referido Estatuto agregou velhas demandas dos professores que há anos reivindicavam uma função que se responsabilizasse pela organização pedagógica e pela articulação coletiva do trabalho nas escolas (FERNANDES, 2009).

Dessa forma, a inclusão da função no Estatuto sob a forma de carreira aberta, já que seria desempenhada por um professor escolhido pelo corpo docente da escola, foi considerada um avanço do ponto de vista da democratização das relações de trabalho, relacionando-se fortemente ao contexto sociopolítico daquele momento. A garantia legal da função permitiria o duplo protagonismo docente: tanto na possibilidade do professor vir a ser o coordenador do processo pedagógico como também de atuar no processo de escolha dos interessados em ocupar a função.

Alguns anos mais tarde, a Resolução n’. 28 (SÃO PAULO, 1996) publicada no âmbito da reforma educacional denominada "São Paulo de Cara Nova", detalhou a justificativa e o perfil dos ocupantes da função de PCP nas escolas, afirmando que deveriam atuar na construção do projeto político pedagógico, na articulação e integração das ações pedagógicas, no acompanhamento e avaliação dos projetos de reforço, nas reuniões coletivas dos docentes voltados ao aperfeiçoamento e atualização em serviço e na articulação entre a Unidade Escolar e a supervisão e no subsídio ao professor no desenvolvimento do seu trabalho (FERNANDES, 2009). A função que, a partir daquele momento deixou de estar vinculada a projetos especiais da pasta, ${ }^{2}$ passou a ser possível a todas as escolas públicas estaduais com mais de 12 salas de aula em funcionamento, nas quais foi desempenhada por professor da rede com mais de três anos de experiência docente aprovado em prova escrita organizada pela SEE/SP e selecionado pelo corpo docente após apresentação de proposta de trabalho específica para a unidade escolar.

Desse momento inicial até a publicação da Resolução 35 (SÃO PAULO, 2000), justificou-se a existência do PCP com o foco de trabalho na unidade escolar onde os ocupantes da função compunham com o diretor e o vice-diretor a equipe responsável pela gestão pedagógica, buscando articular o coletivo em torno de questões fundamentais para o desenvolvimento das ações escolares. Ao analisar as justificativas apresentadas para a existên-

2 A função de coordenação pedagógica já existia na rede estadual paulista desde meados da década de 1960 com a criação dos Ginásios Vocacionais e dos Colégios de Aplicação (FERNANDES, 2009). Entretanto, por um longo período, a função esteve vinculada a projetos especiais e específicos da Secretaria de Estado da Educação, não sendo vislumbrada como possibilidade de trabalho no amplo conjunto das escolas públicas. 
cia da função, observamos que nesse período foi dado destaque à construção/elaboração, desenvolvimento, implantação e avaliação do projeto político pedagógico, bem como, à articulação dos professores em torno do currículo. Verificamos ainda a responsabilidade do PCP pela atualização em serviço dos professores e pelas ações de formação continuada. Assim, as duas Resoluções iniciais - 28/1996 e 76/1997 - guardavam o germe articulador da função que deveria agir coletivamente tendo no horizonte o desenvolvimento da escola a partir das necessidades de seus diferentes sujeitos.

No ano 2000, com a Resolução 35 (SÃO PAULO, 2000), ocorreu uma mudança significativa na função. Além de subtraído legalmente o termo pedagógico da denominação da função, que passou a ser ocupada por um "professor coordenador", ${ }^{3}$ como já analisado por Fernandes (2012), houve redução da atuação do coletivo docente na seleção dos interessados em participar do processo de escolha, uma vez que a "indicação" dos ocupantes da função passou a ser prerrogativa do Conselho de Escola formado por representantes de docentes, especialistas da educação, funcionários, pais e estudantes. A seleção como apresentada pelas Resoluções anteriores remetia à participação direta dos professores e a uma escolha a partir de regras definidas pelos propósitos e princípios estabelecidos pelo corpo docente, observadas, obviamente, a legislação, os quais eram verificados e confrontados com a proposta de trabalho dos candidatos. Dessa forma, os docentes assumiam grande parte da responsabilidade pela escolha daquele que viria a compor a equipe gestora da escola. Ao substituir a "seleção" por "indicação" do Conselho, mesmo considerando o poder deliberativo conferido ao colegiado, reduziu-se a autonomia docente na escolha daqueles que iriam realizar as atividades de articulação pedagógica, até porque o Conselho de Escola passou a dividir a "indicação" com os diretores, sendo os últimos os responsáveis pela definição do perfil do candidato esperado.

Nos anos seguintes, os sujeitos escolares foram perdendo ainda mais o protagonismo no processo de escolha e, no ano de 2006 especificamente, com a publicação da Resolução 66, houve a exclusão da participação docente no processo de indicação do PC. A partir da publicação da supracitada Resolução, a indicação centrou-se na figura do diretor, que com o supervisor escolar passou a analisar os candidatos a partir de um dado perfil estabelecido não mais pela escola, mas pela SEE/SP.

Em 2014, a Resolução 74 explicitou que deveria ser valorizado na indicação "a compatibilização do perfil e qualificação profissional do candidato com a natureza das atribuições relativas ao posto de trabalho a ser ocupado" e "a valorização dos certificados de participação em cursos promovidos por esta Secretaria da Educação". Ao compatibilizar o perfil dos candidatos com as atribuições legais, como veremos adiante, evidenciou-se que o PC deveria controlar e acompanhar o trabalho docente com vistas à eficácia, eficiência e melhoria dos resultados de desempenho escolar. Ao alterar a forma de escolha do PC, reduziram-se as possibilidades de atuação docente nos processos de organização pedagó-

\footnotetext{
3 Apesar da discordância em relação à nova denominação da função, a mesma será utilizada em consonância com a legislação em vigor em cada um dos momentos analisados.
} 
gica das escolas, ficando a cargo dos diretores a decisão individual de considerar ou não as demandas dos professores no momento da indicação, fragilizando o potencial democrático antes embutido na composição da equipe gestora.

A Resolução 66/2006, assim como as publicadas posteriormente, reafirmou a necessidade do candidato ter "perfil" para a função, o que nos levou a um questionamento: será que a referência genérica ao "perfil" abrangia as necessidades pedagógicas dos docentes? Ou seria o perfil uma adequação do $\mathrm{PC}$ ao atendimento das reformas educacionais por parte da SEE/SP? Não teria sido ainda a indicação do perfil uma forma obscura de definição de um PC pautado em critérios individuais, uma vez que, como analisado por Dias-da-Silva e Lourencetti (2002), havia entre PC e diretores reconhecidos conflitos e disputas por território de atuação no espaço escolar?

Acompanhando legalmente as alterações no processo de indicação e avaliação dos professores coordenadores, observamos que as Resoluções indicaram o distanciamento dos órgãos centrais/intermediários e dos próprios gestores escolares das discussões coletivamente estabelecidas com os docentes, reduzindo as margens de autonomia das escolas e de corresponsabilidade nos processos pedagógicos.

A partir da Resolução 88/2007, de modo diferente das resoluções anteriores, estabeleceu-se que os candidatos à função de PC deveriam participar e serem aprovados em prova escrita elaborada pela Coordenadoria de Estudos e Normas Pedagógicas (CENP), a qual deixou de apresentar um rol de bibliografia básica. Antes da referida Resolução, o processo seletivo exigia aprovação dos candidatos, com no mínimo 50\% de acertos, em provas escritas elaboradas pela SEE/SP (Resoluções 26/96 e 76/97) e/ou pelas Diretorias Regionais de Ensino (Resoluções 35/2000 e 66/2006). Tais provas eram obrigatoriamente realizadas após publicação de edital com apresentação de bibliografia mínima relativa à função.

A partir da Resolução n ${ }^{\circ}$.90/2007, a exigência de aprovação em prova escrita deixou de constar na legislação e o critério central para indicação dos PCs pelos diretores e supervisores passou a ser unicamente a entrevista a que os candidatos passaram a se submeter. Um critério, portanto, que se distanciou da participação coletiva, aproximando-se da subjetividade e dos critérios individuais de escolha garantidos pelo atendimento ao "perfil". Além disso, a alteração legal nos levou a inferir que o conhecimento mínimo de conteúdos de natureza didático-pedagógica foi relegado a segundo plano, contrariando a defesa de Pinto (2011) sobre a necessária formação do coordenador pedagógico. Para o referido autor, os ocupantes da função deveriam ter domínio específico do campo de conhecimento pedagógico, o que seria fundamental para o PC se fixar em suas atribuições, não sendo absorvido pelas demandas burocráticas/administrativas.

A própria bibliografia mínima que fora exigida nas provas escritas até o ano de 2007 acompanhou as alterações relativas às atribuições e justificativas para a função de PC, como adiantado por Fernandes (2012). As temáticas e os autores voltados à discussão e construção do projeto político pedagógico (PPP), dimensão fundamental do trabalho educativo e da orientação pedagógica da escola, e à necessária organização do trabalho coletivo, foram substituídos por temáticas que se aproximavam de questões curriculares voltadas à padronização e ao controle do desempenho. 
Nas Resoluções publicadas nos anos de 1996 e 1997, quando a atuação do PC se voltava explicitamente para a articulação pedagógica a partir do PPP, a bibliografia era formada predominantemente (oito em dez indicações) por um conjunto de materiais de origem institucional escrito por nomes conhecidos na área de educação que despontaram no período de discussão sobre a democratização da escola no final da década de 80 e início dos anos 90, como José Cerchi Fusari, Selma Garrido Pimenta, Cipriano Luckesi e Regina Leite Garcia. Os materiais institucionais indicados nas Resoluções iniciais faziam parte de uma série publicada pela Fundação para o Desenvolvimento da Educação (FDE) denominada "Ideias" que teve ampla penetração nas escolas paulistas. Além disso, a bibliografia das provas escritas para a seleção dos PCs era composta pelos cadernos da SEE/SP - Escola de Cara Nova - que explicitavam as diretrizes da reforma educacional e algumas medidas a ela relacionadas, como a organização das salas ambiente, a composição e organização dos conselhos escolares, o planejamento e preparação das Horas de Trabalho Pedagógico Coletivo (HTPC). De maneira geral, a bibliografia exibia como foco questões de natureza didático-pedagógica que permeavam o processo de organização escolar, incentivando a participação e a autonomia dos professores e da equipe gestora na definição dos rumos da escola, indicando, portanto, caminhos possíveis para o trabalho coletivo.

No início dos anos 2000, a bibliografia para a prova escrita que passou a ser composta por 30 questões de múltipla escolha (e não mais 40 questões elaboradas pela SEE/SP) e uma questão objetiva elaborada pelas Diretorias de Ensino, incorporou a nova legislação nacional que fora aprovada na segunda metade dos anos 90, incluindo a Lei de Diretrizes e Bases da Educação Nacional (LDBEN) e o Estatuto da Criança e do Adolescente (ECA). Além disso, a Resolução 35/2000 apresentou uma relação de livros e documentos oficiais que discutiam temas candentes num momento em que os desafios da progressão continuada - estabelecida sem ampla discussão com a rede pública e sem condições favoráveis de implementação - estavam sendo vivenciados pelas escolas. Nesse sentido, a bibliografia incluiu, além dos materiais institucionais relativos à Escola de Cara Nova, textos voltados à discussão de temas especificamente pedagógicos como, planejamento e avaliação. Também foram incluídos temas de natureza sociológica voltados à discussão da disciplina/indisciplina, bem como, a constituição das famílias contemporâneas e seus encontros e desencontros com as escolas. A bibliografia também perpassou questões relativas ao fortalecimento dos Conselhos de Classe e Conselhos de Escola e à importância da gestão colegiada. As questões curriculares ainda estavam presentes e remetiam aos documentos e propostas definidos no final da década de 80 e início dos anos 90, quando houve um intenso movimento na rede estadual paulista, organizado pela CENP, envolvendo professores e universidades com o objetivo de definir objetivos, conteúdos e metodologias para as diferentes áreas do currículo. Observamos, portanto, que a legislação, mesmo que num contexto de reformas educacionais, mantinha o foco do trabalho na escola, considerando-a como lócus fundamental da produção do conhecimento, tanto no tocante à formação do aluno como também do professor.

Na segunda metade dos anos 2000, com a Resolução 66/2006, a preocupação com o desempenho, a eficácia e a eficiência constou explicitamente pela primeira vez na justifi- 
cativa e nas atribuições da função de PC, tendo reflexos na definição da prova escrita. As questões curriculares voltadas ao estabelecimento de um currículo uniformizado, que se constituía naquele momento em objeto central da reforma intitulada "São Paulo faz Escola", apareceram com grande força na bibliografia sugerida aos candidatos à seleção de PC que passou a ser composta unicamente por documentos oficiais da SEE/SP. Além disso, identificamos na seleção forte influência de determinada concepção de educação presente na reforma que propunha o ensino por competências e habilidades, a supervalorização das avaliações externas e a inserção das tecnologias nos processos de ensino. Relacionado a essa nova bibliografia estava a exigência de que o PC atuasse como "gestor implementador da política da SEE/SP" (SÃO PAULO, 2006) a quem caberia fazer, no âmbito da escola, a gestão pedagógica dos objetivos, metas e diretrizes estabelecidos na proposta oficial.

Vimos, dessa forma, que a função de PC sofreu uma forte guinada em suas atribuições e, por conseguinte, em sua natureza, incorporando, do ponto de vista legal, um perfil implementador de propostas estabelecidas externamente, propostas essas vinculadas a um modelo de currículo padronizado e passível de ser controlado a distância por meio das avaliações externas, que, por sua vez, também passaram a ser de responsabilidade dos PCs, já que caberia a eles "elevar o nível de desempenho escolar evidenciado pelos instrumentos de avaliação interna e externa" (SÃO PAULO, 2007), além de serem os "pilares básicos de melhoria da qualidade de ensino" (SÃO PAULO, 2014).

A partir de 2007, quando foi publicada a Resolução $n^{\circ} .88$, a competição, a eficiência e a produtividade foram fortalecidas com um substrato legal que efetivou novas formas de disciplina e novos sistemas éticos nas escolas (BALL, 2005), favorecendo o controle docente e o enquadramento ao modelo proposto pela SEE/SP. Tomando como comparativo a análise do trabalho dos inspetores escolares na Espanha, podemos afirmar que os governos empregaram o uso da lei como instrumento preferente para mudar a escola, uma vez que acreditaram na vigilância normativa como forma de alterar ou construir a realidade (MONARCA; HERNÁNDEZ-GONZÁLEZ, 2016).

Nesse sentido, a coordenação pedagógica no Estado de São Paulo foi legalmente justificada e reafirmada como necessária para a gestão e implementação das políticas oficiais. A defendida autonomia, por exemplo, luta cara aos movimentos docentes, ganhou outro significado nesse contexto e, contraditoriamente, passou a justificar a dimensão individual e controladora do trabalho em detrimento da organização coletiva como aprendizagem social e política (SANTOS, 2017). Para novos projetos, foram atribuídas novas tarefas aos Professores Coordenadores, alterando-se as regras e os rumos do trabalho realizado nas escolas, o que impôs aos ocupantes da função atribuições diferentes daquelas inicialmente apresentadas e partilhadas com os professores. Reconhecemos na legislação que de responsável pela ação articuladora e pelo papel central ocupado no aprimoramento do processo ensino e aprendizagem nas unidades escolares (Resoluções 28/1996 e 76/1997), o PC, de quem passou a ser exigido espírito de liderança e dinamismo (RESOLUÇÃO 75/2014), foi responsabilizado pela otimização dos recursos e pela parceria escola-comunidade (Resolução 35/2000). Na Proposta Curricular do Programa São Paulo faz Escola, o PC é identifi- 
cado como "líder e animador da implementação da proposta curricular nas escolas" (SÃO PAULO, 2007b).

Do PC passou-se a exigir competências para analisar índices e indicadores externos de avaliação de sistema e desempenho das escolas, propagar os projetos e programas da SEE/ SP e propor mudanças para garantir a qualidade do ensino. Uma responsabilização considerável para professores que ao ocuparem a função de coordenação não têm muitas vezes o conhecimento pedagógico mínimo para analisar e trabalhar com os indicadores e que tampouco receberam formação específica para tal, como analisou Vera (2017). Tampouco têm os PCs condições objetivas favoráveis para garantir a qualidade da escola, pois, ao organizar o trabalho, veem limitada sua atuação frente a problemas como rotatividade, itinerância e ausência de professores (DIAS-DA-SILVA e FERNANDES, 2006). Nas resoluções publicadas após o ano de 2007, os PCs passaram a ser cobrados ainda pela elevação dos níveis de desempenho escolar expressos nos resultados das avaliações externas, inserindo-se a função numa lógica que retirou a possibilidade da escola de definir seus objetivos e ações, como já analisaram Cunha, Barbosa e Fernandes (2015). Dessa forma, as resoluções publicadas no âmbito do Programa São Paulo faz Escola indicaram mais claramente a atuação gerencial dos PCs a quem caberia monitorar o trabalho docente e disseminar as propostas oficiais indicadas oficialmente. A perspectiva de trabalho assentou-se num modelo uniforme de organização pedagógica que não considerou as especificidades e dificuldades das unidades escolares.

Mais recentemente, os PCs passaram a realizar o monitoramento e controle de um número consideravelmente maior de salas de aulas, o que acarretou em intensificação de um trabalho já reconhecido como intenso (FERNANDES, 2009). De 1996 a 2006, segundo determinações legais, a escola podia ter um ou dois Professores Coordenadores atuando de acordo com o número de salas em funcionamento, sendo um PC para o diurno, em escolas com o mínimo de 12 salas, e um para o noturno, caso houvesse dez ou mais salas em funcionamento no período. Os dois PCs atuavam em conjunto em função da elaboração, desenvolvimento e avaliação do Projeto Político Pedagógico, procurando dar sentido e significado ao trabalho coletivo.

A partir de 2007, a coordenação passou a ser organizada não mais por período de aulas, mas por segmentos de ensino, e assim foi destacado um PC para os Anos Iniciais que atuavam com no mínimo seis salas de aula; um PC para os Anos Finais do Ensino Fundamental e Ensino Médio desde que houvesse também o mínimo de oito salas e, caso a escola tivesse mais de trinta salas no total, contava com três Professores Coordenadores. Em 2016, as escolas passaram a contar com dois PCs, desde que no total dos períodos de funcionamento houvesse mais de 30 salas de aula, juntando-se os três segmentos de ensino: Anos Iniciais, Anos Finais do Ensino Fundamental e Ensino Médio. No final de 2016, com vigência para o ano de 2017, foi estabelecida mais uma mudança, sendo necessário o mínimo de oito salas de aula para a existência da função e, nos casos em que não havia turmas dos Anos Iniciais, a escola passou a contar com apenas um Professor Coordenador para trabalhar com até 30 salas de aulas. Havendo mais de 31 turmas e sendo ofertado classes dos Anos Iniciais, existiria, no máximo, dois Professores Coordenadores. 
Considerando-se que as escolas públicas estaduais paulistas apresentam elevado número de alunos por salas e um trabalho docente marcado por rotatividade e precarização (BARBOSA e FERNANDES, 2016), agravaram-se as condições de intensificação da função de PC. Como responsabilizar-se por buscar bons resultados em situações nas quais as condições objetivas impossibilitam o trabalho coletivo e a organização pedagógica? A lógica do fazer mais com menos chegou à coordenação pedagógica. Vemos, portanto, que não importam as condições para a realização do trabalho articulador, já que o foco legal da função não é mais a organização pedagógica das escolas a partir de seu PPP (aliás, a retirada do "pedagógico" da denominação da função faz cada vez mais sentido), mas, sim, a implementação e o acompanhamento de medidas reformistas desprovidas da atuação ativa e consequente dos sujeitos escolares. O PPP tornou-se um instrumento legal, que no cotidiano esvaziou-se de sentido e significado, perdendo seu potencial como instrumento de luta e forma de contraposição à fragmentação do trabalho pedagógico, à rotinização e ao poder autoritário e centralizador dos órgãos da administração central (VEIGA, 1995, p. 22). O labirinto legal no qual a função foi envolvida ao longo de um período de mais de vinte anos a afastou de sua natureza como prática viabilizadora, integradora e articuladora do trabalho pedagógico-didático em ligação direta com os professores (LIBÂNEO, 2004, p. 219).

\section{CONSIDERAÇÕES FINAIS}

A análise da legislação específica acerca da função de PC no Estado de São Paulo nos remete a uma série de reflexões sobre este trabalho, mas também acerca dos rumos das medidas políticas tomadas nas duas últimas décadas, afinal, as alterações vivenciadas no trabalho não estão descoladas do projeto educacional que há mais de duas décadas vigora na rede pública de ensino. A função eminentemente articuladora e voltada para o exercício de atividades pedagógicas relacionadas às necessidades específicas das escolas foi apropriada com outros objetivos e intenções ao longo de vários anos de implantação de uma perniciosa política educacional gerencialista e performática. Por meio de diferentes resoluções, a coordenação pedagógica foi vinculada a formas tradicionais e burocráticas de administração escolar, embora disfarçadas sob um discurso democrático e autônomo. Os aspectos legais conduziram a função para o controle e monitoramento docente, assumindo múltiplas tarefas que alteraram, em nome de uma suposta qualidade, a natureza do trabalho e fragilizaram sua identidade.

Num movimento de ampliação do controle e monitoramento das escolas para a implementação do currículo oficial e obtenção de índices de desempenho nas avaliações externas, as reformas gerencialistas e performáticas se apropriaram da função, reduzindo os espaços tradicionalmente marcados pela autonomia e atuação ativa dos PCs e dos professores. Se nas Resoluções iniciais o foco do trabalho de coordenação era a elaboração e desenvolvimento do Projeto Político Pedagógico definido a partir do diagnóstico da própria escola e dos objetivos de aprendizagem dos alunos, passou, com o tempo, a ser o atendimento às de- 
terminações estabelecidas externamente e voltadas para os índices de desempenho. Dessa forma, os espaços de desenvolvimento profissional e fortalecimento da autonomia escolar foram não só reduzidos, mas também controlados de fora para dentro. Assim, mais do que reformas técnico-estruturais, aspecto discutido por Ball (2002), as medidas legais levaram à reforma do próprio significado do trabalho realizado pelos Professores Coordenadores. Nesse sentido, ter uma atuação autônoma e desafiadora frente ao legalmente estabelecido pelas sucessivas resoluções torna-se cada vez mais difícil e dependente de formas individuais de ajuste, de interpretação e reinterpretação, frente às determinações legais.

\section{REFERÊNCIAS}

BALL, S. J. Profissionalismo, gerencialismo e performatividade. In: Cadernos de Pesquisa, São Paulo, v. 35, p. 539-564, set./dez. 2005.

BALL, S. J. Reformar escolas/reformar professores e os terrores da performatividade. In: Revista Portuguesa de Educação, Braga, v. 15, n. 2, p. 3-23, 2002.

BARBOSA. A. FERNANDES, M. J. S. O piso salarial em São Paulo: desvalorização dos professores. In: Retratos da Escola, Brasília, v. 10, n. 18, p. 243-274, jan.jun. 2016.

CUNHA, R. C. O. B.; BARBOSA, A.; FERNANDES, M. J. S. Implicações das avaliações externas para o trabalho docente coletivo. In: Estudos em Avaliação Educacional, v. 26, n. 62, p. 386-416, mai./ago. 2015.

DIAS-DA-SILVA, Maria Helena Galvão Frem; FERNANDES, Maria José da Silva. As condições de trabalho dos professores e o trabalho coletivo: mais uma armadilha das reformas educacionais neoliberais? In: Seminário da Redestrado, VI, 2006. Anais eletrônicos... Rio de Janeiro, 2006.

FERNANDES, M. J. S. O professor coordenador pedagógico e a fragilidade da carreira. In: Estudos em Avaliação Educacional, v. 20, n. 44, p. 411-424, set./dez. 2009.

FERNANDES, M. J. S. O professor coordenador pedagógico nas escolas estaduais paulistas: da articulação pedagógica ao gerenciamento das reformas educacionais. In: Educação e Pesquisa, v. 38, n. 4, p. 799-814, out./dez. 2012.

LIBÂNEO, J. C. Organização e gestão da escola: teoria e prática, 5. ed. Goiânia: Alternativa, 2004.

MONARCA, H.; FERNÁNDEZ-GONZALÉZ, N. El papel de la inspección educativa em 
los procesos de cambio. In: Cadernos de Pesquisa. São Paulo, v. 46, n. 159, p. 212-233, jan./mar. 2016.

PEREIRA, L. C. B. Burocracia pública e reforma gerencial. In: Revista do Serviço Público. Brasília, p. 29-48, 2007.

PINTO, U. A. Pedagogia escolar: coordenação pedagógica e gestão educacional. São Paulo: Cortez, 2011.

RUSSO, M. H. Trabalho e administração da escola: desenvolvimento e apropriação do sentido que assumem no processo de produção pedagógica. In: Revista Brasileira de Política e Administração da Educação. Porto Alegre, v. 27, n. 3, p. 495-519, set./dez. 2011.

SANTOS, V. F. Condições de trabalho docente no ensino fundamental II na rede estadual paulista e representações de professores sobre autonomia, 2017. Dissertação (Mestrado em Educação). Universidade Federal de São Paulo, Guarulhos, 2017.

SÃO PAULO (Estado). Secretaria de Estado da Educação. Estatuto do Magistério. São Paulo, SP, 1985.

SÃO PAULO (Estado). Secretaria de Estado da Educação. Resolução SE nº. 28/1996. Dispõe sobre o processo de seleção, escolha e designação de docente para exercer as funções de Professor Coordenador, em escolas da rede estadual de ensino e dá providências correlatas. SP, 1996.

SÃO PAULO (Estado). Secretaria de Estado da Educação. Resolução SE no. 76/1997. Dispõe sobre o processo de seleção, escolha e designação de docente para exercer as funções de Professor Coordenador, em escolas da rede estadual de ensino. SP, 1997.

SÃO PAULO (Estado). Secretaria de Estado da Educação. Resolução SE no . 35/2000. Dispõe sobre o processo de seleção, escolha e designação de docente para exercer as funções de Professor Coordenador, em escolas da rede estadual de ensino e dá providências correlatas. SP, 2000.

SÃO PAULO (Estado). Secretaria de Estado da Educação. Resolução SE n⿳0 66/2006. Dispõe sobre o processo de seleção, escolha e designação de docente para exercer as funções de Professor Coordenador, em escolas da rede estadual de ensino. SP, 2006.

SÃO PAULO (Estado). Secretaria de Estado da Educação. Resolução SE $\mathbf{n}^{\mathbf{0}}$. 88/2007. Dispõe sobre a função gratificada de professor coordenador. SP, 2007. 
SÃO PAULO (Estado). Secretaria de Estado da Educação. Resolução SE $\mathbf{n}^{\mathbf{0}}$. 90/2007. Dispõe sobre função gratificada de professor coordenador nas quatro séries finais do Ensino Fundamental e no Ensino Médio, em escolas da rede estadual de ensino. SP, 2007.

SÃO PAULO (Estado). Secretaria de Estado da Educação. Resolução SE $\mathbf{n}^{\mathbf{0}}$. 53/2010. Altera dispositivos da Resolução SE nº. 88/2007, e da Resolução SE nº. 21/2010, que dispõem sobre a função gratificada de professor coordenador. SP, 2010.

SÃO PAULO (Estado). Secretaria de Estado da Educação. Resolução SE n ${ }^{0}$. 75/2014. Dispõe sobre a função gratificada de Professor Coordenador. SP, 2014.

SÃO PAULO (Estado). Secretaria de Estado da Educação. Resolução SE no . 03/2015. Altera dispositivos da Resolução SE 75, de 30-12-2014, que dispõe sobre a função gratificada de Professor Coordenador. SP, 2015.

SÃO PAULO (Estado). Secretaria de Estado da Educação. Resolução SE n⿳0. 12/2016. Altera a Resolução SE 75, de 30-12-2014, que dispõe sobre a função gratificada de Professor Coordenador. SP, 2016.

SÃO PAULO (Estado). Secretaria de Estado da Educação. Resolução SE no . 65/2016. Altera a Resolução SE 75, de 30-12-2014, que dispõe sobre a função gratificada de Professor Coordenador. SP, 2016.

VEIGA, I. P. A. Projeto político-pedagógico da escola: uma construção coletiva: In: VEIGA, I. P. A. (Org.). Projeto político-pedagógico da escola: uma construção possível. Campinas: Papirus, 1995.

VERA, R. F. A formação continuada do Professor Coordenador na rede pública estadual paulista de ensino regular, 2017, 116s. Dissertação (Mestrado em Educação Escolar). Faculdade de Ciências e Letras. Universidade Estadual Paulista "Júlio de Mesquita Filho", Araraquara, 2017.

Maria José da Silva Fernandes

Doutora em Educação Escolar. Professora da Universidade Estadual Paulista Júlio de Mesquita Filho (UNESP). Lotada no Departamento de Educação-FC/Bauru e no Programa de Pós-Graduação em Educação Escolar-FCL/Araraquara. E-mail: mj.fernandes@unesp.br

Submetido em: 2-1-2018

Aceito em: 5-6-2018 